\title{
Fabrication of Tungsten Carbide Alloy Micro-pin with Environment-Responsive ECM Using Ultra-low Concentration Electrolyte
}

\author{
Naoki SHIBUYA*, Wataru NATSU* \\ (Received December 24, 2011) \\ * Department of Mechanical System Engineering, Tokyo University of Agriculture and Technology, \\ Tokyo 184-8588, Japan
}

\begin{abstract}
This study describes a method to fabricate tungsten carbide alloy pins of diameters from 14 to $60 \mu \mathrm{m}$ with the machining time about $12 \mathrm{~min}$ by environment-responsive electrochemical machining (ECM) using an ultra-low concentration electrolyte. To improve machining accuracy, pin rotation and ultrasonic washing during machining were adopted. It was realized that thinner pins with better axial symmetry were obtained with the rotation and ultrasonic washing. Furthermore, the effect of electrolyte concentration was investigated by using a $\mathrm{NaNO}_{3}$ aqueous solution. It was observed that by-product adhesion to pins reduced by using a $\mathrm{NaNO}_{3}$ aqueous solution over a certain concentration and the machining speed was improved by increasing the current, which increased electrical conductivity.
\end{abstract}

Key words: ECM, micro-pin, tungsten carbide alloy, mineral water, ultrasonic washing, electrolyte concentration

\section{INTRODUCTION}

Micro-machining technologies are in demand to keep pace with the rapid changes in precision equipment technology (e.g., communications devices and medical devices). Among the components of precision mechanical equipment, micro-pins are of wide application to micro-tools and micro mold components. For example, when high-aspect-ratio holes are machined with electric discharge machining (EDM), micro electrodes with smaller diameters and higher aspect ratios are required because of tool wear ${ }^{1)}$. To fabricate micro-pins, the following methods are suggested: turning, EDM, ultrasonic machining, and grinding $^{2-7)}$. Each machining method has its advantages and disadvantages. In turning, although the machining speed is high, the machining of tungsten carbide alloy is difficult, because the workpiece material is limited to easy-to-cut materials such as brass ${ }^{2)}$. In EDM, the following methods are proposed to fabricate micro-pins: wire electro discharge grinding (WEDG) ${ }^{3)}$, machining with self-drilled holes ${ }^{4)}$, and scanning $\mathrm{EDM}^{5 \text { ) }}$. Although the machining accuracy is affected by tool wear and slow machining speed, all metallic material can be machined precisely regardless of the material hardness. In ultrasonic machining, micro-pins made of nonconductive materials can be machined to a smooth surface. This is because ultrasonic machining is a type of mechanical machining that uses the loose grain. However, the machining speed is slow and the tool wear is unavoidable because of the press force added to the tool from the workpiece by the intermediary of the abrasive grain ${ }^{6}$. In grinding, it has been reported that a $1 \mu \mathrm{m}$ diameter micro-pin was fabricated by grasping the pin at both ends and using bicipital grinding wheels ${ }^{7)}$. With grinding methods other than this special process, fabricating micro-pins with high aspect ratios is difficult because of the higher machining force.

The problems encountered in both thermal and mechanical machining can be overcome with ECM. There is no tool wear and almost all metallic material can be machined regardless of the material hardness. When tungsten carbide alloy is machined with ECM, tungsten carbide can be removed by using a $\mathrm{NaOH}$ solution as an electrolyte ${ }^{8)}$. Although there are several reports about the fabrication of tungsten carbide alloy micro-pins by using acidic and alkaline electrolytes ${ }^{9), 10)}$, such electrolytes are harmful to operators and cause environmental problems. To solve these problems, the authors have attempted to use a neutral electrolyte for micro-machining of tungsten carbide alloy with $\mathrm{ECM}^{11)}$. As a result, it was reported that in micro-pin fabrication with ECM, high-aspect-ratio micro-pins could be obtained in shorter machining time by using a $\mathrm{NaNO}_{3}$ aqueous solution. It was also reported that to further reduce environmental impacts, pins can be fabricated by using mineral water $^{12)}$, which is readily available at low cost. However, the reproducibility of the machining shape is poor, and the fabrication of micro-pins with uniform diameters is difficult because of the local current concentration. This is because the by-products adhering to the pin during machining prevented the machining current from flowing equally through the pin. Hence, in this report the effect on machining shape due to the reduction of the by-product adhesion was investigated during 
machining by applying pin rotation and ultrasonic washing. Furthermore, to verify the effects of electrolyte concentration on the by-product adhesion and machining shape, the characteristics of the pin fabrication when using a $\mathrm{NaNO}_{3}$ aqueous solution as the neutral electrolyte were investigated.

\section{EXPERIMENTAL SETUP}

The schematic of the system for micro-pin fabrication is shown in Figure 1 (a). It consists of an XYZ stage, a rotating spindle, and a high-voltage power source, which is required for the high-resistance electrolyte. The pin is mounted in the rotating spindle whose position can be controlled in the $x, y$, and $z$ directions. The positional relationship of the micro-pin and tool is shown in Figure 1 (b). The pin faces the SUS304 plate electrode, and the bottom surface of the plate and the end of the pin lie at the same height. A commercially available ultrasonic washing machine is used as the electrolyte tank. Pin rotation and ultrasonic washing during machining effectively remove the bubbles and other by-products from the inter-electrode area, stabilizing the fabrication process. Also, constant current provided by the power source guarantees the same dissolved mass per unit time. The pin rotation also improves the axial symmetry of the pin. The physical properties of the mineral water used in the experiments are

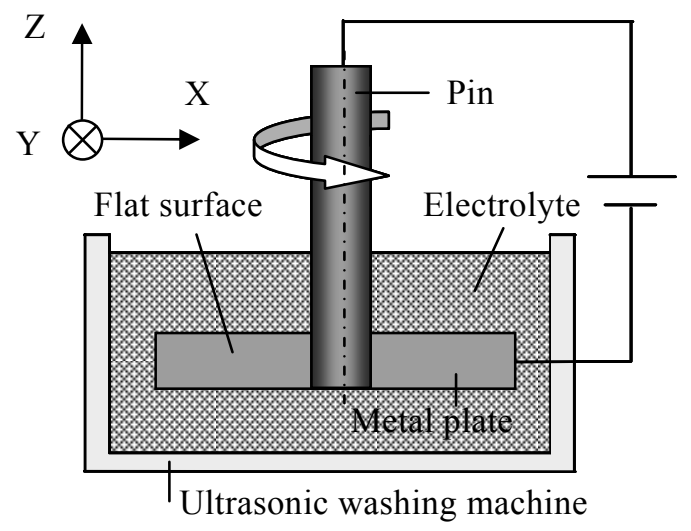

(a) Experimental setup

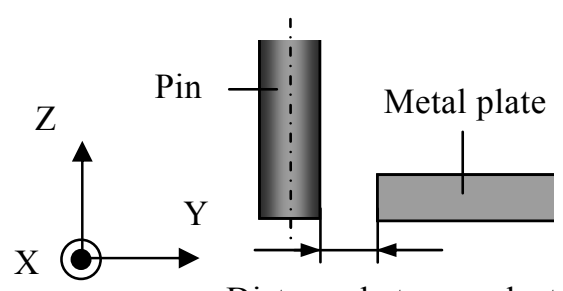

Distance between electrodes

(b) Position of pin and metal plate

Fig.1 Setup of fabricating micro-pin shown in Table 1, and the compositions of the mineral water are shown in Table 2 .

Table 1 Physical properties of mineral water used in experiments

\begin{tabular}{c|c}
\hline Electric conductivity [S/m] & 0.014 \\
\hline $\mathrm{pH}$ & 7 \\
\hline Water hardness & 33.1 \\
\hline
\end{tabular}

Table 2 Compositions of mineral water (mg per $100 \mathrm{ml}$ )

\begin{tabular}{c|c}
\hline $\mathrm{Na}$ & 1.25 \\
\hline $\mathrm{Ca}$ & 0.85 \\
\hline $\mathrm{K}$ & 0.10 \\
\hline $\mathrm{Mg}$ & 0.29 \\
\hline
\end{tabular}

\section{REDUCTION OF BY-PRODUCT ADHESION BY PIN ROTATION AND ULTRASONIC WASHING}

In this experiment, tungsten carbide alloy was machined with mineral water and $\mathrm{NaNO}_{3}$ aqueous solution in accordance with the following machining principle ${ }^{8}$. When using a mixture of $\mathrm{NaCl}$ and $\mathrm{NaOH}$ as electrolyte, cobalt is dissolved according to reaction (1). Tungsten carbide is oxidized according to reaction (2) or (3), and $\mathrm{WO}_{3}$ is dissolved according to reaction (4). It is also expected that since mineral water and $\mathrm{NaNO}_{3}$ aqueous solution contain $\mathrm{Na}^{+}$ions, the application of mineral water and $\mathrm{NaNO}_{3}$ aqueous solution can offer similar reactions to the solution containing $\mathrm{NaCl}$. In this study, in order to machine tungsten carbide alloy without $\mathrm{NaOH}$, the adhesion of generated $\mathrm{WO}_{3}$ to the pin surface is reduced by the physical action of pin rotation and ultrasonic washing.

$$
\begin{aligned}
& \mathrm{Co}+2 \mathrm{Cl}^{-} \rightarrow \mathrm{CoCl}_{2}+2 e \\
& \mathrm{WC}+6 \mathrm{OH}^{-} \rightarrow \mathrm{WO}_{3}+\mathrm{C}+3 \mathrm{H}_{2} \mathrm{O}+6 e \\
& \mathrm{WC}+6 \mathrm{OH}^{-} \rightarrow \mathrm{WO}_{3}+\mathrm{CO}_{2}+5 \mathrm{H}_{2} \mathrm{O}+10 e \\
& \mathrm{WO}_{3}+2 \mathrm{NaOH} \rightarrow \mathrm{Na}_{2} \mathrm{WO}_{4}+\mathrm{H}_{2} \mathrm{O}
\end{aligned}
$$

The machining conditions are shown in Table 3 and the properties of WC alloy are shown in Table 4. Machining was carried out at a constant current both with and without pin rotation and ultrasonic washing to determine the reduction effect of the by-product adhesion under conditions with and without pin rotation and ultrasonic washing. Figure 2 shows white products adhering to the pins both without the pin rotation and ultrasonic washing (Figure 2 (a)) and with pin rotation and ultrasonic washing (Figure 2 (b)). Since the volume of the compound $\mathrm{WO}_{3}$, generated due to oxidation reaction, increases several times comparing to $\mathrm{WC}$ and adheres to the surface, the pin tip seems like a flower in case (a). Furthermore, the wrinkle-line is 
observed on the surface because the by-products are peeled in layers. By comparing cases (a) and (b), it is found that by-product adhesion could be reduced by pin rotation and ultrasonic washing.

Table 3 Machining conditions

\begin{tabular}{c|c}
\hline Electrolyte & Mineral water \\
\hline Machining current $[\mathrm{mA}]$ & 50 \\
\hline Machining time $[\mathrm{min}]$ & 8 \\
\hline Rotation speed $[\mathrm{rpm}]$ & 2850 \\
\hline Electrodes distance $[\mu \mathrm{m}]$ & 350 \\
\hline Pin material & $\phi 300 \mu \mathrm{m}$ WC alloy \\
\hline Metal plate & $\mathrm{t} 2 \mathrm{~mm}$ SUS304
\end{tabular}

Table 4 Properties of WC alloy

\begin{tabular}{c|c}
\hline Grain size $[\mu \mathrm{m}]$ & 0.5 \\
\hline Composition of Co $[\%]$ & $10 \sim 13$ \\
\hline
\end{tabular}

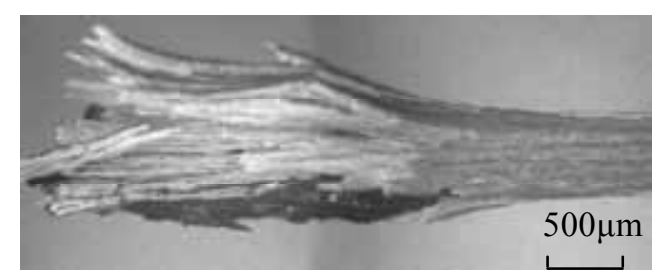

(a) Without rotation and ultrasonic

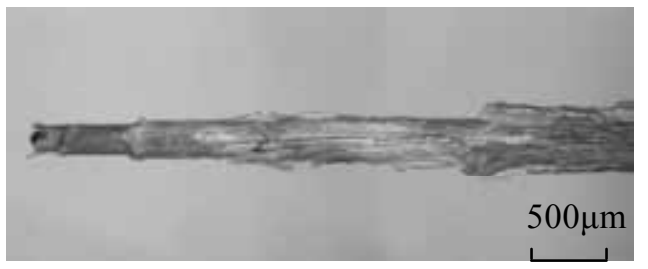

(b) With rotation and ultrasonic washing

Fig. 2 By-product adhesion to pin surface under different conditions

\section{IMPROVEMENT TO MACHINING ACCURACY BY REDUCTION OF BY-PRODUCT ADHESION}

4.1 Effect of pin rotation and ultrasonic washing The preceding section verifies the reduction of the by-product adhesion by pin rotation and ultrasonic washing. In this section, the effects of pin rotation and ultrasonic washing on fabricated shape are shown. Micro-pins were machined at a constant current under the machining conditions shown in Table 3.

Figure 3 shows the fabricated micro-pins under different conditions. Just after the machining, pins were covered by the by-products, as shown in Figure 2. Figure 3 shows pins after removing the by-products by further ultrasonic washing after machining. In Figure 3, it is observed that the micro pins have non-uniform diameters in cases without pin rotation and ultrasonic washing (Figure 3 (a)) and with pin rotation only (Figure 3 (b)). This is because the current tends to concentrate on areas of large curvature owing to the existence of the by-products in the gap area and by-product adhesion to the pins. As a result, the pins were eroded locally. Even without rotation, the pin was fabricated at an area where the pin did not face the metal plate, as shown in Figure 3 (a). This is believed to occur because the machining current also flowed in the area with a large gap width. Meanwhile, it can be observed from Figure 3 (c) that the fabricated pin has a more uniform diameter. It shows that the electric current did not concentrate locally, because of the reduction of by-product adhesion by ultrasonic washing. However, the pin is slightly eccentric to the central line. It is believed that a larger current flowed in the area of narrow gap width, and the removal amount was higher here than that in other areas. Figure 3 (d), which shows both pin rotation and ultrasonic washing, indicates that the diameter along the central line is more uniform and the shape is more axisymmetric. It can be concluded that the pin rotation contributes to the roundness improvement and the ultrasonic washing contributes to the uniform diameter.

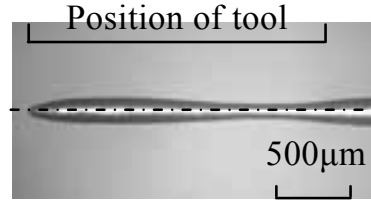

(a) Without rotation and without ultrasonic

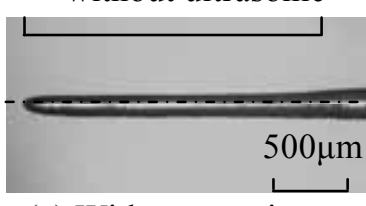

(c) Without rotation with ultrasonic

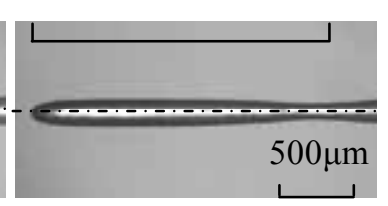

(b) With rotation without ultrasonic

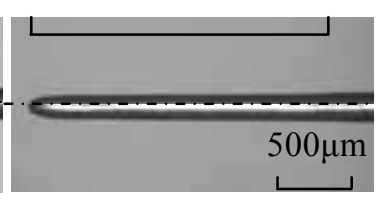

(d) With rotation and with ultrasonic
Fig. 3 Micro-pin fabricated by ECM with different condition

\subsection{Effect of electrolyte temperature on ultrasonic washing}

It was reported that the effect of ultrasonic washing changes with the solution temperature, according to the combination of the washed object and the wash solution ${ }^{13)}$. The chemical reaction rate also changes greatly with the temperature. The influence of electrolyte temperature on the machining characteristics was therefore investigated by changing the temperature from $20{ }^{\circ} \mathrm{C}$ to $50{ }^{\circ} \mathrm{C}$. The pins were machined with a constant current under the machining conditions 
shown in Table 3. Pin rotation and ultrasonic washing were applied consistently. Before starting machining process, the ultrasonic washing machine was used to heat the electrolyte to the setup temperature. During machining, the electrolyte temperature rose due to ultrasonic washing. However, for each setup temperature, the rise in the temperature was around $5{ }^{\circ} \mathrm{C}$, which is smaller than the temperature width of the setup temperature. Therefore, the influence of the rise in temperature during machining was ignored.

Figure 4 shows change in the diameter under different electrolyte temperatures. The horizontal axis shows the distance from the end of the micro-pin. It is observed that the overall diameters decreased in proportion to the rise in temperature. One reason for this decrease in the case of high electrolyte temperatures is considered to be the acceleration of the chemical reaction. Another reason is that the machining current flowed easily due to the reduction of by-products adhesion, because ultrasonic washing is more effectively conducted at a temperature of about $50{ }^{\circ} \mathrm{C}{ }^{13)}$. Meanwhile, it is found that at an electrolyte temperature of $50{ }^{\circ} \mathrm{C}$, the diameter becomes non-uniform near the corner of the plate tool (ranging from 1600 to $2000 \mu \mathrm{m}$ in Figure 4). It is thought that the effectiveness of the ultrasonic washing degraded, because the electrolyte temperature might have exceeded the optimal temperature due to the temperature rise caused by ultrasonic washing during machining. Thus, the pin was machined locally because the machining current concentrated near the corner of the metal plate. Considering the machining accuracy and the machining speed, an electrolyte temperature of $40{ }^{\circ} \mathrm{C}$ is thought to be optimal under these experimental conditions.

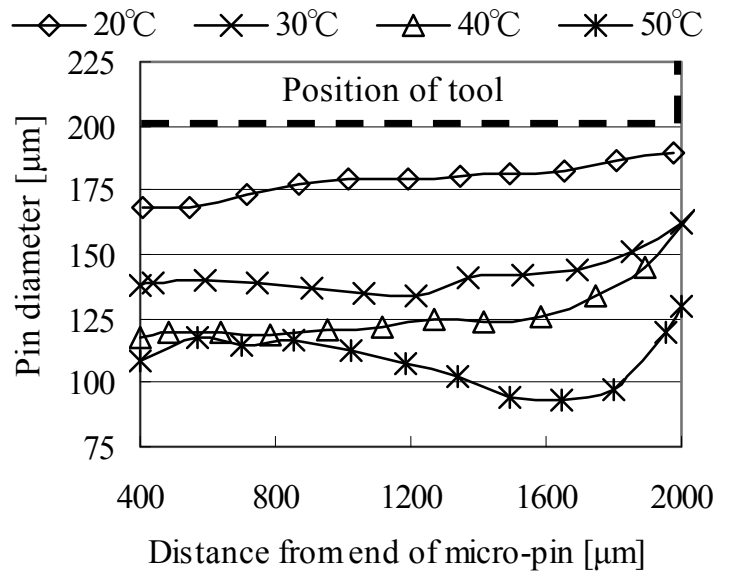

Fig. 4 Relationship between temperature and pin diameter

\section{MICRO-PIN \\ FABRICATION \\ WITH MINERAL WATER}

When the by-product adhesion was not reduced, the pin fractured at a small-diameter area where the pin was eroded locally. Therefore, a pin of uniform diameter cannot be fabricated because the end of the pin becomes thinner after it fractures. However, according to Section 3, localized erosion was reduced greatly when by-product adhesion was reduced by pin rotation and ultrasonic washing. Thus, to obtain a smaller pin diameter, a pin was fabricated at a constant current under the machining conditions shown in Table 3. Pin rotation and ultrasonic washing were applied consistently during machining.

Figure 5 shows the shape of the pin at a machining time of $11.8 \mathrm{~min}$, and Figure 6 shows the relationship between micro-pin diameter and machining time. The diameters were measured at the end of the pin. It was observed that the micro-pin was fabricated with no localized machining although the pin became a little thinner towards the end. Also, pin diameter becomes smaller in proportion to the machining time. Figure 6 shows that a $14 \mu \mathrm{m}$ diameter micro-pin could be obtained from a $300 \mu \mathrm{m}$ pin in $11.8 \mathrm{~min}$.

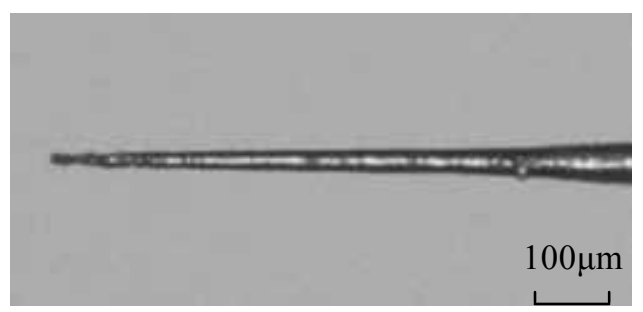

Fig. 5 Micro-pin fabricated in machining time of $11.8 \mathrm{~min}$

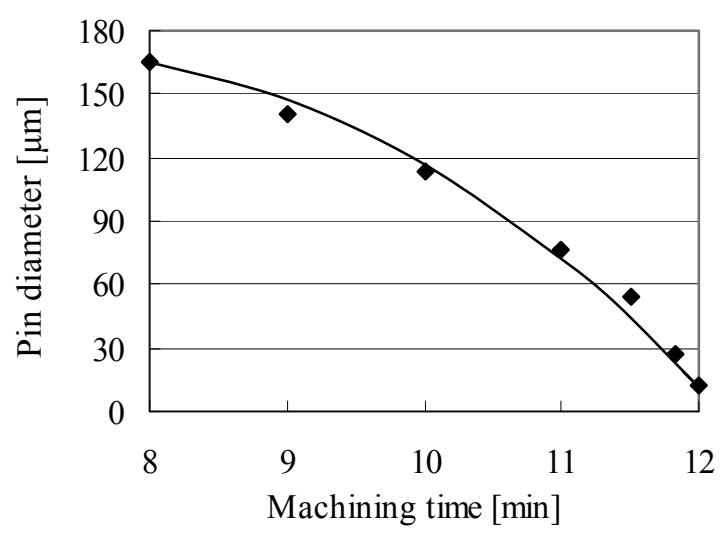

Fig. 6 Relationship between machining time and pin diameter 


\section{RELATIONSHIP BETWEEN ELECTROLYTE CONCENTRATION AND BY-PRODUCT ADHESION}

In the preceding section, it was shown that micro-pins of tungsten carbide alloy could be fabricated with mineral water by applying pin rotation and ultrasonic washing. Also, as mentioned in sections 3 and 4, it was shown that by-products adhering to the micro-pin were not removed completely, although the machining accuracy was improved by pin rotation and ultrasonic washing during machining. Furthermore, the effects of electrolyte property and electrolyte concentration on by-product adhesion are unknown, and by-product adhesion is expected to reduce exponentially by optimizing both the effects. Moreover, it is shown in Figure 6 that more than 10 min of machining is necessary to obtain a micro-pin with a diameter of about $15 \mu \mathrm{m}$ from a $300 \mu \mathrm{m}$ pin. The machining speed is slow because the machining current is limited by the ultra-low electrical conductivity of mineral water. Hence, in this section, to reveal problems associated with ECM using mineral water and to provide countermeasures, the effects of the electrolyte concentration and the machining current on by-product adhesion and machining speed were investigated by using a neutral electrolyte $\mathrm{NaNO}_{3}$ aqueous solution.

The electrolyte concentration was changed from $0.1 \%$ to $10 \%$, and the machining was carried out with the current constant. In the mineral water case, the available supply current is $100 \mathrm{~mA}$ when using a constant current power source whose highest voltage is $120 \mathrm{~V}$. However, a larger current can be obtained by using a $\mathrm{NaNO}_{3}$ aqueous solution and the same power source. So the current was set to $400 \mathrm{~mA}$, which was four times higher than when using mineral water. The other machining conditions are the same as in Table 3, and pin rotation and ultrasonic washing were expected to have the same effect as in the mineral water case.

Figure 7 shows the positional relationship between the metal plate and the micro pin under different electrolyte concentrations. To compare pin shapes under different concentrations, pins with nearly identical diameters were selected and are shown in Figure 7. The machining time for each pin is also shown in the figure. In Figure 7, the photos of (a), (c), and (e) were taken immediately after machining, while the photos of (b), (d), and (f) were taken after further ultrasonic washing after machining. Figure 8 shows the change in pin diameter under different concentrations of electrolyte. The diameters shown in Figure 8 were measured at the positions marked by dashed lines in
Figure 7 . Except at the $0.1 \%$ concentration, the change in diameter is not shown because the pin fractured during machining. It is realized from Figure 7 that the higher the electrolyte concentration is, the greater is the prevention of by-product adhesion. At the $10 \%$ concentration, by-product adhesion is not observed. The reason is thought to be as follows. At low electrolyte concentration, the current was concentrated predominantly at the pin end and the pin part near the corner of the metal plate, because these two portions have large curvatures where the current

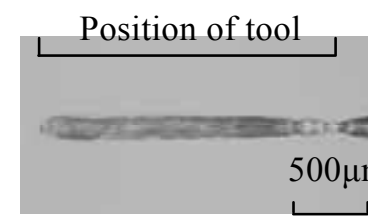

(a) $0.1 \%, 100 \mathrm{~s}$ machining before further washing
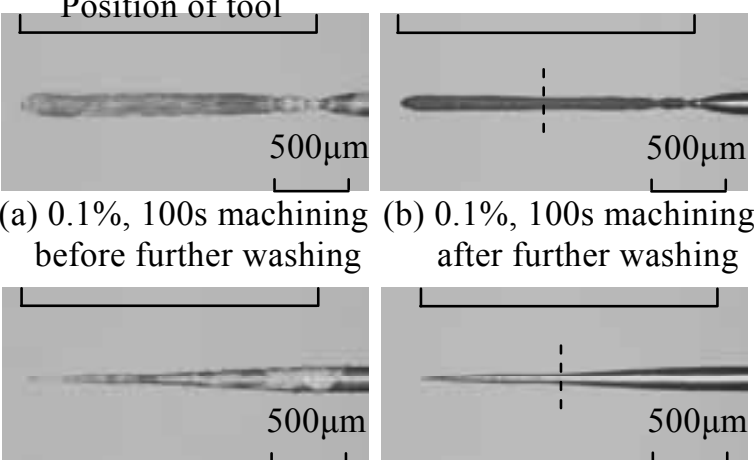

(b) $0.1 \%, 100 \mathrm{~s}$ machining after further washing

(c) $1.0 \%, 100 \mathrm{~s}$ machining before further washing
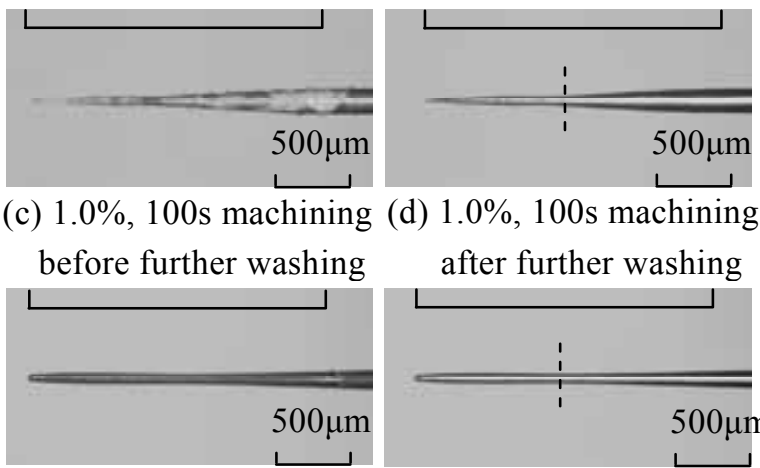

(d) $1.0 \%, 100 \mathrm{~s}$ machining

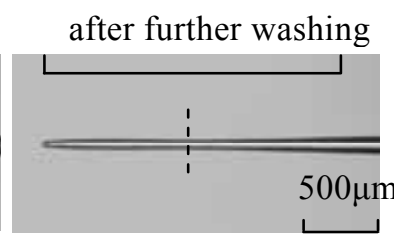

(e) $10 \%, 150 \mathrm{~s}$ machining (f) $10 \%, 150 \mathrm{~s}$ machining before further washing after further washing

Fig. 7 Micro-pin fabricated under different concentrations and machining times

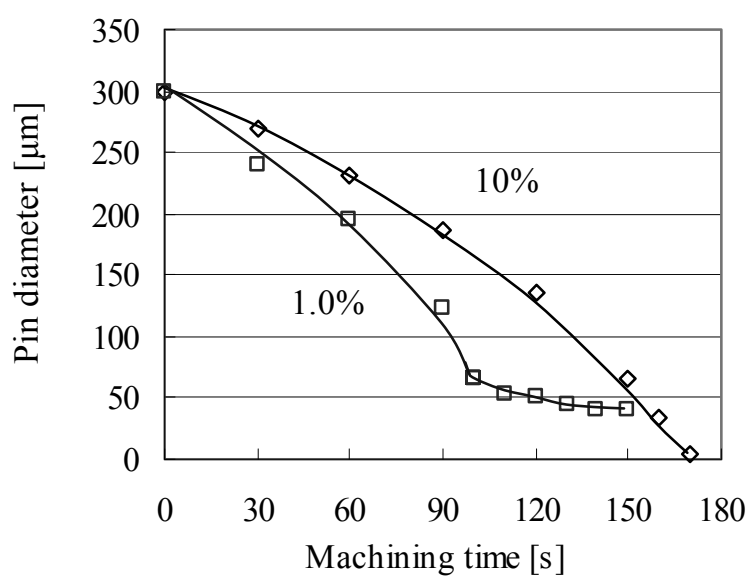

Fig. 8 Relationship between machining time and pin diameter under different concentrations 
tends to concentrate. For example, at $0.1 \%$ concentration, the diameter is not uniform. Meanwhile, when mineral water, which is considered as an ultra-low concentration electrolyte, was used, a uniform diameter was obtained as shown in Figure 3 (d)). The difference may be caused by the different properties of mineral water and $\mathrm{NaNO}_{3}$ solution. It can be observed from Figure 8 that the pin diameter becomes smaller in proportion to machining time. Moreover, at $10 \%$ concentration, a micro-pin with a diameter of about $10 \mu \mathrm{m}$ can be obtained from a $300 \mu \mathrm{m}$ pin in about $3 \mathrm{~min}$, and the machining speed was improved exponentially.

\section{CONCLUSIONS}

Tungsten carbide alloy micro-pins were fabricated by using less harmful and corrosive mineral water and $\mathrm{NaNO}_{3}$ aqueous solution. The following conclusions can be drawn from the experimental results.

- Micro-pins with a uniform diameter and a small eccentricity can be obtained by using mineral water and applying the pin rotation and ultrasonic washing.

- There is an optimal temperature for machining speed and pin shape, because the electrolyte temperature affects the reaction rate and ultrasonic washing.

- Pin diameter can be controlled by the machining time.

- When using an electrolyte at ultra-low concentration, new measures to reduce by-product adhesion are required. This is because the experimental result shows a $\mathrm{NaNO}_{3}$ aqueous solution over a certain concentration is necessary to inhibit by-product adhesion on the micro-pins.

\section{ACKNOWLEDGEMENT}

This work was supported by Grant-in-Aid for Scientific Research (B), JSPS (No.23360064).

\section{REFERENCES}

1) H. Yamashita, T. Nishikawa, Study of Precision Machining (8 Report) Evaluation of machining conditions for micro hole with high aspect ratio, Study Report of Hiroshima Prefectural Western Region Industrial Research Center, No.44(2001), pp.16-19 (in Japanese).

2) H. S. Lee, A. Toride, T. Yamada, S. Araki,
Study on the generation of micro shafts by turning operation, Journal of the Japan Society for Abrasive Technology, Vol.51, No.11(2007), pp.657-661 (in Japanese).

3) T. Masuzawa, M. Fujino: Wire Electro Discharge Grinding for Micro-machining, Annals of the CIRP, Vol.34/1, (1985), pp.431-434.

4) M. Yamazaki, T. Suzuki, N. Mori, M. Kunieda: EDM of micro-rods by self-drilled holes, Journal of Materials Processing Technology, Vol.149 (2004), pp.134-138.

5) T. Tani, H. Gotoh, J. K. Lee, N. Mouri, Micro-pin Forming Method by Scanning EDM, Journal of The Japan Society of Electrical Machining Engineers, Vol.43, No.104(2009), pp.187-193 (in Japanese).

6) K. Egashira, T. Taniguchi, K. Nishimura, H. Tsuchiya, M. Miyazaki, Ultrasonic machining of micropins, Journal of the Japan Society for Abrasive Technology, Vol.50, No.11(2006), pp.649-653 (in Japanese).

7) T. Naruse, Y. Uehara, Y. Watanabe, K. Katahira, W. Lin, H. Ohmori, M. Norihide, N. Itoh, Y. Yamamoto, Development of micro tool by ELID micro-fabrication system 5th report: The highly efficient processing of micro tool, Journal of the Japan Society for Abrasive Technology, Vol.50, No.5(2006), pp.285-290 (in Japanese).

8) T. Masuzawa, M. Kimura: Electrochemical Surface Finishing of Tungsten Carbide Alloy, Annals of the CIRP, Vol.40/1,pp.199-202.

9) Y. M. Lim, S. H. Kim, An electrochemical fabrication method for extremely thin cylindrical micopin, International Journal of Machine Tools and Manufacture 41, (2001), pp.2287-2296

10) S. H. Choi, S. H. Ryu, D. K. Choi, C. N. Chu, Fabrication of WC micro-shaft by using electrochemical etching, The International Journal Advanced Manufacturing Technology, (2007), pp.682-687.

11) N. Shibuya, Y. Ito, W. Natsu: Research on ECM Conditions for Micro-pin Fabrication of Tungsten Carbide Alloy, International Symposium on Green Manufacturing and Applications 2011, (2011).

12) Y. Yang, W. Natsu, W. Zhao: Realization of eco-friendly electrochemical micromachining using mineral water as an electrolyte, Precision Eng., 35,(2011),pp.204-213.

13) A.S.Bebchuk et al., All Union Conf.Ultrasonics, Dom Tekhniki, Moscow (1957). 